\title{
Diagnosis of gastrointestinal obstruction in dogs and cats using ultrasound - a retrospective study of 38 cases
}

\author{
JACEK MADANY, ANDRZEJ MILCZAK, KAROLINA WRZEŚNIEWSKA, \\ MARIA TERESA BALASTEGUI MARTINEZ*
}

\author{
Department and Clinic of Animal Internal Diseases, Faculty of Veterinary Medicine, \\ University of Life Sciences, 30 Głęboka Street, 20-612 Lublin, Poland \\ *Department of Animal Medicine and Surgery, Faculty of Veterinary Medicine, \\ Universidad Cardenal Herrera - CEU, C/Santiago Ramón y Cajal, s/n, 46115 Alfara del Patriarca, Valencia, Spain
}

Madany J., Milczak A., Wrześniewska K., Balastegiu Martinez M. T. Diagnosis of gastrointestinal obstruction in dogs and cats using ultrasound - a retrospective study of 38 cases

\section{Summary}

GI obstruction often leads to intractable vomiting, the consequences of which can be life-threatening. For diagnosing, an ileus clinical examination with abdominal radiographs or ultrasonographs are chosen routinely. The purpose of the study was to determine the incidence of GI obstruction among animals with gastrointestinal symptoms and to define ultrasonographic accuracy in detecting these GI obstructions.

38 animals (31 dogs and 7 cats) were included in the study. At the first consultation they presented gastrointestinal symptoms. A clinical examination with palpation of the abdomen was made. An ultrasound examination was made by an experienced radiologist.

17 of the 38 animals were diagnosed with obstructive ileus. In 15 of these 17 the ileus was confirmed, and in the remaining 2 only functional obstruction and enteritis was found. For the other 21 of the 38 animals the ileus was excluded. The animals with GI obstruction accounted for $39.5 \%$ of all animals with GI symptoms. The ultrasound examination was effective in $88.2 \%$ of cases.

Intestinal obstruction is common in patients with gastrointestinal symptoms. Vomiting, diarrhoea and constipation are the main symptoms. Abdomen pain is rare. Ultrasound is a valuable and safe method for detecting GI obstructions. In only 2 animals was ileus misdiagnosed.

Keywords: GI obstruction, dogs, cats, symptoms, USG examination

Gastrointestinal (GI) obstruction is a life-threatening condition that should always be considered in the differential diagnosis of dog and cat diseases involving acute and chronic GI symptoms. Mechanical or functional obstruction leads to local circulatory obstruction, water-electrolyte abnormalities, hypovolemia and shock. Complications may include intestinal perforation, tissue necrosis, peritonitis, toxaemia and death. GI obstruction in dogs and cats is often caused by the anatomical predisposition in the intestinal structure of small animals and their constant presence in a human environment, one conducive to the swallowing of inappropriate and inedible objects $(1,2,7,8,19)$.

An early diagnosis of GI obstruction improves prognosis. Clinical symptoms of obstruction are not specific and depend on the location, degree of obstruction and developing disorders in fluid circulation. In order to make the final diagnosis, imaging methods are used: $\mathrm{x}$-ray and/or ultrasound. The only effective solution is surgical or endoscopic removal of the cause of the obstruction $(1,12,13,19)$.

The aim of the study is a clinical analysis of animals with GI symptoms, determination of GI obstruction frequency and evaluation of the diagnostic value of ultrasound examinations in the determination of such diagnosis.

\section{Material and methods}

The study was performed on 38 animals (31 dogs and 7 cats) of different breeds, including mixed breeds of both 
sexes, aged between 4 months and 14 years, examined by the Clinic of Animal Internal Diseases, Faculty of Veterinary Medicine of the University of Life Sciences, Lublin, Poland.

The animals were brought in for examination due to clear symptoms from the GI tract. The animals were subjected to a full clinical examination. On the basis of the history and physical examination, the animals were referred in an outpatient procedure, without prior preparation, for an abdominal ultrasound examination, which indicated a GI obstruction. The examination was performed by an experienced radiologist using MyLab ${ }^{\mathrm{TM}}$ Class $\mathrm{C}$ - Esaote, Aloka ProSound SSD 4000 equipment. A 7.5 MHz linear probe was used in most animals, while a low frequency $<6 \mathrm{MHz}$ convex and microconvex probe was used in 2 cats. The study was performed after the animals had been placed in a supine position in accordance with the existing recommendations.

The main ultrasound criteria for the diagnosis of GI obstruction were: presumed image of a foreign body, presence of a "target sign", presence of a pendulous flow of content within the dilated intestine, the "accordion sign", segmental dilatation of the intestine, gas or fluid-filled intestine, presence of free peritoneal fluid and presence of cholestasis. The ultrasound examination also indicated the presence of pain caused by the compression of the probe on the abdominal wall.

The animals with the ultrasound-confirmed presence of obstruction were referred for surgical treatment. The animals in which obstruction was excluded were subjected to clinical re-evaluation and further diagnostics followed by intense conservative treatment.

\section{Results and discussion}

The examined dogs and cats showed acute and chronic symptoms from the GI tract. The clinical trial analysed the main and accompanying symptoms. The evaluated primary symptoms included vomiting (34/38), constipation lasting more than 3 days (20/38), diarrhoea (19/38), abdominal distension $(5 / 38)$, abdominal pain (4/38), rectal pressure (3/38) and dark coloured stools (3/38). At least three or more primary symptoms were present in 38 animals, as shown in Table 1. GI obstruction was suspected in all animals on the basis of an interview and a clinical trial with abdominal palpation. Next, an abdominal ultrasound was performed. A total of 17 animals were diagnosed with GI obstruction, and 21 were not. The main ultrasound symptoms used as diagnostic criteria are shown in Table 2. During the ultrasound examination, 7 dogs had pain reactions due to compression by the probe. In one of the 17 animals with diagnosed obstruction, the condition subsided during the preoperative preparation and after the implementation of intensive fluid therapy. Eventually, 16 animals were referred for surgical treatment.

In 15 cases the applied treatment confirmed the obstruction, whereas in 1 case it did not. In 12 cases the obstruction was caused by foreign bodies and in 3 cases by intussusception of the intestine. In those animals with foreign bodies, in 4 cases they were removed from the stomach by endoscopy, and in 8 cases surgically after performing a laparotomy. Apart from the foreign bodies in the stomach, 8 were located in the intestines: 4 in the duodenum, 3 in the jejunum, and 1 in the colon. The foreign bodies included: fragments of clothes in 5 cases, fragments of sponge in 2 cases, walnuts in 2 cases, plastic toy elements in 1 case, a single linen thread in 1 case, and solidified cement deposits in 1 case. In 3 cases of intestinal intussusception, a segmental resection with end-to-end anastomosis was performed.

In 21 animals the ultrasound image did confirm the obstruction. In these cases, the diagnostic criteria for ultrasound imaging were not met and/or other causes explaining the clinical signs were detected.

The results of the clinical analysis indicate that 15 out of 38 animals were affected by gastric and/or intestinal obstruction. This represents $39.5 \%$ of animals admitted with vomiting, diarrhoea and/or constipation. The presence of foreign bodies was the cause of obstruction in $80 \%$ of cases, with intussusception accounting for the remaining $20 \%$ of the cases.

Tab. 1. The incidence of clinical manifestations of major clinical symptoms in dogs and cats suspected of gastrointestinal obstruction $(\mathrm{n}=\mathbf{3 8})$

\begin{tabular}{|l|c|}
\hline \multicolumn{1}{|c|}{ Analysed GI symptoms } & Incidence \\
\hline Vomiting & $34 / 38$ \\
\hline Constipation for longer than 24 hours & $20 / 38$ \\
\hline Diarrhoea & $19 / 38$ \\
\hline Abdominal distension & $5 / 38$ \\
\hline Abdominal pain & $4 / 38$ \\
Rectal pressure & $3 / 38$ \\
\hline Dark coloured stools & $3 / 38$ \\
\hline
\end{tabular}

Tab. 2. Frequency of the occurrence of relevant ultrasound symptoms in animals with and without obstruction after laparoscopic confirmation

\begin{tabular}{|l|c|c|c|}
\hline \multicolumn{1}{|c|}{ Ultrasound symptom } & $\begin{array}{c}\text { Number of animals } \\
\text { with the symptom }\end{array}$ & $\begin{array}{c}\text { Animals with surgically } \\
\text { confirmed obstruction }\end{array}$ & $\begin{array}{c}\text { Animals without } \\
\text { obstruction }\end{array}$ \\
\hline "Target sign" & 5 & 4 & 1 \\
\hline Presumed outline of a foreign body & 14 & 6 & 8 \\
\hline "Accordion sign" & 1 & 1 & 0 \\
\hline Segmental intestinal dilations & 18 & 12 & 6 \\
\hline Fluid-filled loops in bowel & 7 & 6 & 1 \\
\hline Free peritoneal fluid & 8 & 6 & 1 \\
\hline Cholestasis & 5 & 1 & 4 \\
\hline
\end{tabular}

Explanation: "Target sign" - intussusception, the appearance is generated by concentric alternating echogenic and hypoechogenic bands 
The evaluation of the diagnostic value of ultrasound imaging indicates $88.2 \%(15 / 17)$ effectiveness and, by taking into account the correct diagnosis of subsiding obstruction before surgery, the result increases to $94.1 \%(16 / 17)$.

During the medical examination, the animals showed GI symptoms. Vomiting, diarrhoea and constipation dominated in more than half of all the animals (19-34/38). Other symptoms described in the course of obstruction were relatively rare: abdominal distension, increased tension of the abdominal wall with rectal pressure and pain during palpation with the possibility of indicating the area of obstruction (3-5/38). The outlined clinical picture, with the prevalence of three highly non-specific symptoms, did not enable a precise diagnosis. Apart from obstruction, the list of differential diagnoses included local inflammations and general metabolic, infectious and neoplastic diseases. The dominance of vomiting, diarrhoea and constipation in the course of obstruction in the dogs and cats observed in the studies is consistent with previous observations $(1,7,8,12,13)$. However, on the basis of deep palpation, it is rare to find pain and indication of the area of obstruction, which was only possible in individual cases. This observation confirms that pain is only "occasional", "sporadic", or "rare", which is confirmed by other authors $(1,17,19)$. It is also worth noting that the number of pain reactions increased from 4 to 7 animals after the abdominal ultrasound, involving compression exerted by the probe. Ultimately, obstruction was only confirmed in 4 of them. The results indicate the rare incidence and low specificity of pain as a symptom of GI obstruction.

The decision to perform a quick ultrasound examination in the surgery was made because of the advantages of this method over conventional radiography, which is indicated by numerous authors. These advantages include: lack of ionising radiation, no need for anaesthesia, shortened examination time, ability to observe intestinal mobility, visualization of intestinal wall layers and examination of adjacent structures such as lymph nodes, pancreas, liver and spleen, which are usually not visible radiologically $(6,9,14,15,18)$.

The ultrasound examination was performed in accordance with existing guidelines for imaging of abdominal organs in dogs and cats with suspected obstruction $(4,5,10,11,15,16)$. In this study, 33 out of the 38 examined animals showed at least one ultrasound sign of GI obstruction. In many animals several ultrasound symptoms were observed. Eventually, it was decided that 17 animals had GI obstruction, which were then referred for surgery. In one of these animals the obstruction subsided during the preoperative therapy. In the ultrasound image of this animal, a "target sign" was observed, suggesting an intussusception of the intestine. In this case, however, it should be assumed that the diagnosed obstruction was functional rather than mechanical, and the improvement took place after the water-electrolyte imbalance was corrected and proper intestinal motility was restored.

Surgical procedures were performed in 16 animals, the presence of obstruction was confirmed in 15 animals while in 1 animal it was not. In the case of the animal with unconfirmed obstruction, the ultrasound image also showed a "target sign". However, laparotomy showed that the lesions were inflammatory and also a segmental, acute, diffuse swelling of the small intestine wall. Macroscopic changes could explain the possibility of the formation of an ultrasound image with many concentric circles resembling the "target sign" symptom to some extent. This lesion was the reason for the diagnostic error.

Foreign bodies were found in 12 animals: 4 in the stomach $(33.3 \%)$ and 8 in the intestines $(66.7 \%)$. The anatomical distribution of foreign bodies observed coincides with the observations of other authors $(1,3$, $7,12,13)$. After a study on a large group of animals, Hayes, similarly to other authors, stated that $63 \%$ of all foreign bodies in dogs are located in the jejunum.

The clinical analysis of the animals with symptoms of vomiting, diarrhoea and constipation indicates that GI obstruction occurred in as many as $39.5 \%$ of the animals. The obtained result is higher than the results previously demonstrated. Manczur et al. (9) showed obstruction in $29.5 \%$ of animals, Sharma et al. (15) in $33 \%$ and Fromme et al. (5) in $24.6 \%$ in a recent study. The result of the study indicates that serious, life-threatening obstruction in dogs and cats persists, even with a tendency for quantitative growth. It seems therefore appropriate that this phenomenon be monitored and its importance periodically referred to as a clinical, diagnostic and therapeutic problem in the treatment of small animals.

The ultrasound examination performed during these studies showed an efficacy of $88.2 \%$ and thus its clinical usefulness in the diagnosis of GI obstruction was confirmed. Similar results were obtained by other authors $(5,9,14,15,17)$. Among them, Sharma et al. (15) reported up to $97 \%$ efficacy. The result of these studies should therefore be considered satisfactory and the examination itself safe and effective for diagnosing GI obstruction in dogs and cats.

\section{References}

1. Alenspach K., Gaschen F. P.: Choroby jelit cienkich, [in:] Steiner J. M. (ed.): Choroby przewodu pokarmowego psów i kotów. Vol. 1, Galaktyka, Łódź 2009, p. 183-198.

2. Boag A. K., Coe R. J., Martinez T. A., Hughes D.: Acid-Base and Electrolyte Abnormalities in Dogs with Gastrointestinal Foreign Bodies. J. Vet. Intern. Med. 2005, 19, 816-821.

3. Capak D., Simpraga M., Maticić D., Bali R., Janoska B.: Incidence of foreignbody-induced ileus in dogs. Berl. Munch. Tierartztl. Wochenschr. 2001, 114, 290-296.

4. Finck C., D'Anjou M. A., Alexander K., Beauchamp G.: Radiographic diagnosis of mechanical obstruction in dogs based on relative small intestinal external diameters. Vet. Radiol. Ultrasound. 2014, 55, 472-479.

5. Fromme V., Köhler C., Menzel A. K., Alef M., Kiefer I.: Ultrasonographic accuracy in detecting intestinal foreign body's in dogs and cats. Ultraschall in Med. 2016, 37, 1-12. 
6. Gaschen L.: Diagnostyka obrazowa, [in:] Steiner J. M. (ed.): Choroby przewodu pokarmowego psów i kotów. Vol. 1, Galaktyka, Łódź 2009, p. 21-30.

7. Hayes G.: Gastrointestinal foreign bodies in dogs and cats: a retrospective study of 208 cases. J. Small Anim. Pract. 2009, 50, 576-583.

8. MacPhail C.: Gastrointestinal obstruction. Clin. Tech. Small Anim. Pract. 2002, 17, 178-183.

9. Manczur F., Vörös K., Vrabély T., Wladár S., Németh T., Fenyves B.: Sonographic diagnosis of intestinal obstruction in the dog. Acta Vet. Hung. 1998, 46, 35-45.

10. Mapletof E. K., Allenspach K., Lamb C. R.: How useful is abdominal ultrasonography in dogs with diarrhoea. J. Small Anim. Pract. 2018, 59, 32-37.

11. Mattoon J. S., Nyland T. G. (ed.): Small Animal Diagnostic Ultrasound. Vol. 1, Elsevier Sanders, St. Louis 2015, p. 481-490.

12. Mudado M. A., Carlo R., Pacheca A., Borges B., Renato P.: Digestive tract obstruction in pets attended in a Veterinary Hospital during 2010. Revista Ceres. 2012, 59, 434-445.

13. Papazoglou L. G., Patsikas M. N., Rallis T.: Intestinal foreign bodies in dogs and cats. Compend Contin Educ Pract Vet. 2003, 25, 830-844.
14. Patsikas M. N.: Ultrasonographic investigation of the intestinal obstruction in dogs and cats. WSAVA Congress Proceedings, Rhodes 2004.

15. Sharma A., Thompson M. S., Scrivani P. V., Dykes N. L., Yeager A. E., Freer $S$. R., Erb H. N.: Comparison of radiography and ultrasonography for diagnosing small-intestinal mechanical obstruction in vomiting dogs. Vet. Radiol. Ultrasound. 2011, 52, 248-255.

16. Silva A. C., Pimenta M., Guimarães L. S.: Small bowel obstruction: what to look for. Radiographics 2009, 29, 423-439.

17. Tams T., Seim H. III: Gastrointestinal foreign body obstruction in dogs. Western Veterinary Conference, Los Angeles 2013.

18. Tyrrell D., Beck C.: Survey of the use of radiography vs. ultrasonography in the investigation of gastrointestinal foreign bodies in small animals. Vet. Radiol. Ultrasound. 2006, 47, 404-408.

19. Willard M. D.: Choroby żołądka, Choroby jelit, [in:] Nelson R. W., Couto C. G. (ed.): Choroby wewnętrzne małych zwierząt. Vol. 2, Elsevier, Wrocław 2009 , p. $475-526$.

Corresponding author: Karolina Wrześniewska DVM, ul. Glęboka 30, 20-612 Lublin, Poland; e-mail: karolina.wrzesniewska@up.lublin.pl 